\title{
An empirical study on different factors influencing information technology adoption for auditing purposes: A case study of a banking organization
}

\author{
Mehdi Taghavi $^{\mathrm{a}}$, Mohammad Khodaei Valahzaghard ${ }^{\mathrm{b} *}$ and Younes Pourmoradi $^{\mathrm{c}}$
}

\begin{abstract}
${ }^{a}$ Prof., Department of Management, School of Management and Human Sciences, Tehran North Branch, Islamic Azad University (IAU), Tehran, Iran ${ }^{b}$ Assist. Prof. \& Faculty Member, Department of Accounting, School of Management and Human Sciences, Tehran North Branch, Islamic Azad University (IAU), Tehran, Iran

${ }^{c}$ M.Sc. Student, Department of Management, School of Management and Human Sciences, Tehran North Branch, Islamic Azad University (IAU), Tehran, Iran

C H R O N I C L E

Article history:

Received October 27, 2012

Received in revised format

29 January 2013

Accepted 18 February 2013

Available online

February 202013

Keywords:

Auditing systems

Information technology

Ease of use

TAM

A B S T R A C T

In this survey, we have investigated whether an easy and comprehensive information technology (IT) infrastructure could contribute on auditing system in Iranian business society. The survey designs and distributes a questionnaire based on technology adoption method (TAM) among employees of bank Melli Iran who participated in our survey in Likert scale and using t-student and Kruskal-Wallis test examined different hypotheses. The results of our survey have indicated that there was a relationship between a good perception in usefulness of IT implementation and accepting recent advances of IT and auditors with good perception on IT are able to take advantage of recent advances of IT in their auditing skills. In addition, our survey has concluded that ease of IT implementation could create motivation among auditors to automate their traditional skills. While educational background played an important role on our survey, age and job experience did not have any impact on our survey.
\end{abstract}

(C) 2013 Growing Science Ltd. All rights reserved.

\section{Introduction}

During the past few years, there have been growing interests in adopting information technology (IT) as well as technology adoption method (TAM) in different business models such as auditing systems. However, there are always some concerns on investigating the impact of various factors on IT adaptation (Ajzen \& Fishbein, 1972; Ajzen, 1991; Agarwal \& Prasad, 1999; Agarwal et al., 2000; Carter, 2001; Mathieson et al., 2001). Bandura (2002), for instance, investigated growing primacy of human agency in adopting of electronic advances. Burton-Jones and Hubona (2005) studied individual differences and usage behavior and emphasized that people's reaction is important for technology adoption.

Corresponding author. Tel: +98-912-3443139

E-mail: m_khodaei@iau-tnb.ac.ir (M. Khodaei Valahzaghard)

C 2013 Growing Science Ltd. All rights reserved.

doi: $10.5267 /$ j.msl.2013.02.014 
Many people believe that e-government is the one of the most effective ways for reducing fraud in governmental agencies (Hassan et al., 1998; Carter \& Belanger, 2003). Carter and Belanger (2003) investigated the utilization of e-governmental services by studying citizen trust, innovation and acceptance factors. Tung and Rieck (2005) examined adoption of electronic government services among business organizations in Singapore. The ease of use of IT applications is also believed to be a main factor for adoption of IT infrastructures in business models (Davis, 1989; Gefen \& Straub, 2000; Gefen et al., 2003). Training plays an essential role in implementation of IT in new industries (Gist et al., 1989) and Web based applications could contribute on IT implementation, significantly (Glassberg, 2000). A good design perspective for computer integrated facilities could improve productivity and efficiency (Hendrick \& Brown, 1984). Digital libraries, for instance, are examples of the best adaptation of advances of IT technology for accessing knowledge. Hong et al. (2002), for example, determined user acceptance of digital libraries in an empirical and examinational of individual differences and system characterizes. Lee et al. (2003) reviewed some relative literature on ease of use for ease of acceptance in technology development. Karahanna and Straub (1999) performed an empirical investigation on the psychological origins of perceived usefulness and ease of use and Lai and Li (2005) examined technology acceptance model for internet banking using an invariance analysis and described that ease of use plays an important for the acceptance of internet banking.

One of the important features in online banking is the ease of use through mobile banking (Ndubisi, 2005; McCormick \& Martinko, 2004). Luarn and Lin (2005) explained the relative importance of online banking and explained how important is to understand the behavioral intention to use mobile banking. Pikkarainen et al. (2004) examined various factors, which could motivate customers for online banking. Wang et al. (2003) in other survey examined different factors influencing online banking.

\section{The proposed study}

In this paper, we use technology adoption method (TAM) to examine the effect of different factors on adoption of information technology in banking sector. The proposed study of this paper has been implemented for Bank Melli Iran. The proposed study of this paper designs and distributes a questionnaire in terms of Likert scale in seven different scales from completely disagree to completely agree. There are three hypotheses associated with the proposed study of this paper as follows,

1. There is a meaningful relationship between a good perception in usefulness of using information technology and accepting recent advances of information technology for internal auditing.

To answer this question we consider the two questions where the first one looks to find out how much IT implementation could increase employees' performance and the second question investigates how much it is useful for employees.

2. There is a meaningful relationship between accepting IT and ease of IT implementation.

To examine this hypothesis, again, the study considers two questions where the first one examines whether it is easy learn IT and the second question studies whether it is easy to implement IT, practically.

3. There is a meaningful relationship between accepting IT for internal auditing and confidence that IT features could completely address auditors' needs. 
Finally, to verify this hypothesis, we look for two questions of whether characteristics specified for IT implementation are sufficient and whether it covers auditors' needs in their jobs. Fig. 2 demonstrates the results of our survey for the first questions of the first hypothesis.

The first part of this research is associated with 68 people's personal characteristics who filled all questionnaires, properly.

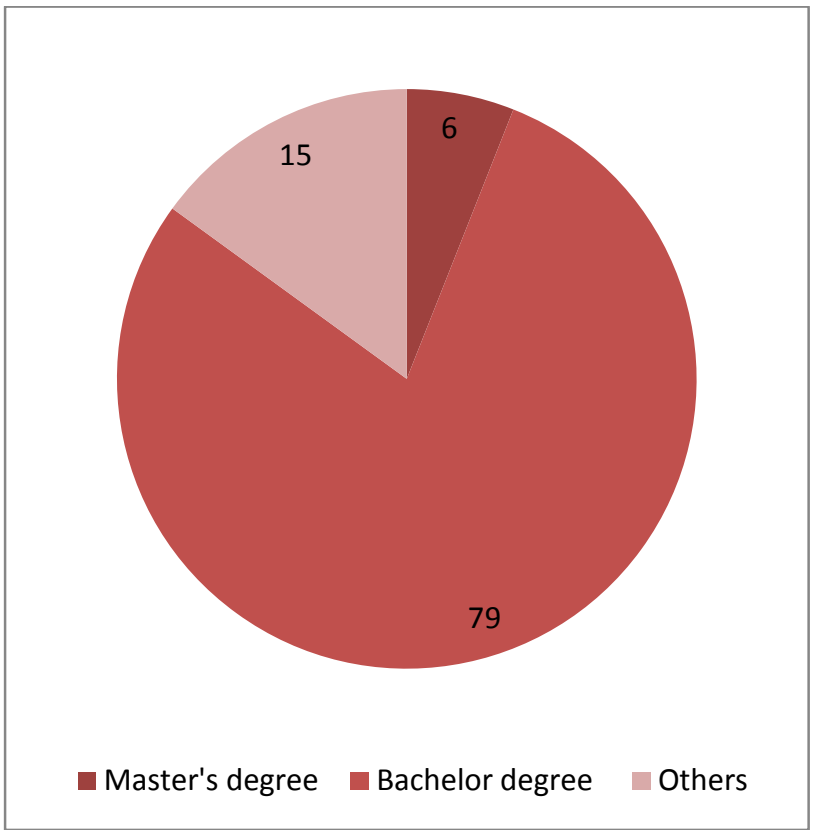

Fig. 1.(a) Educational background

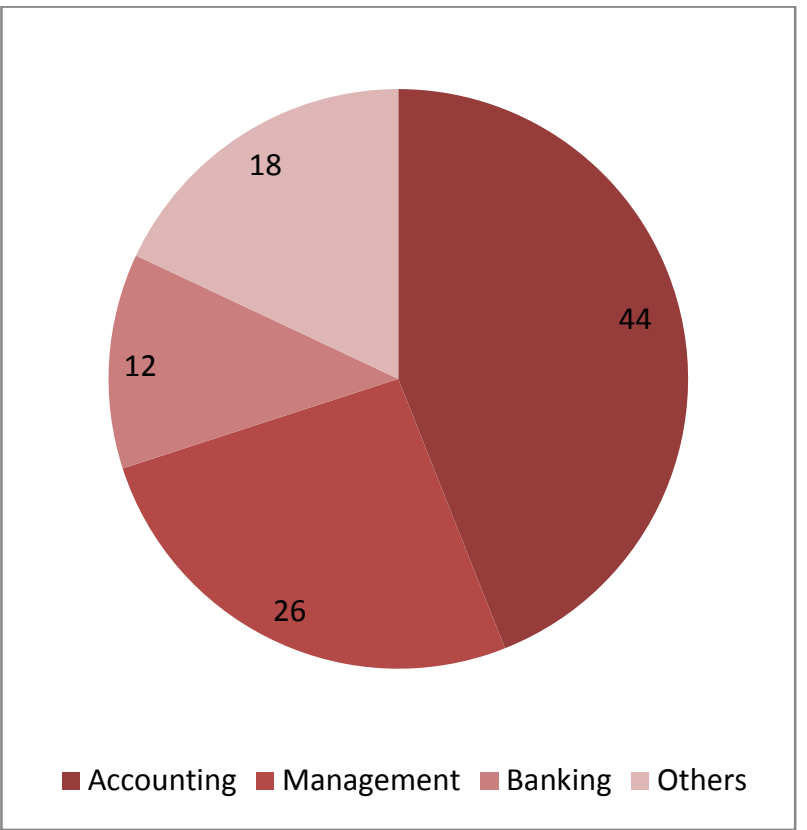

Fig. 1.(b) Area of studies

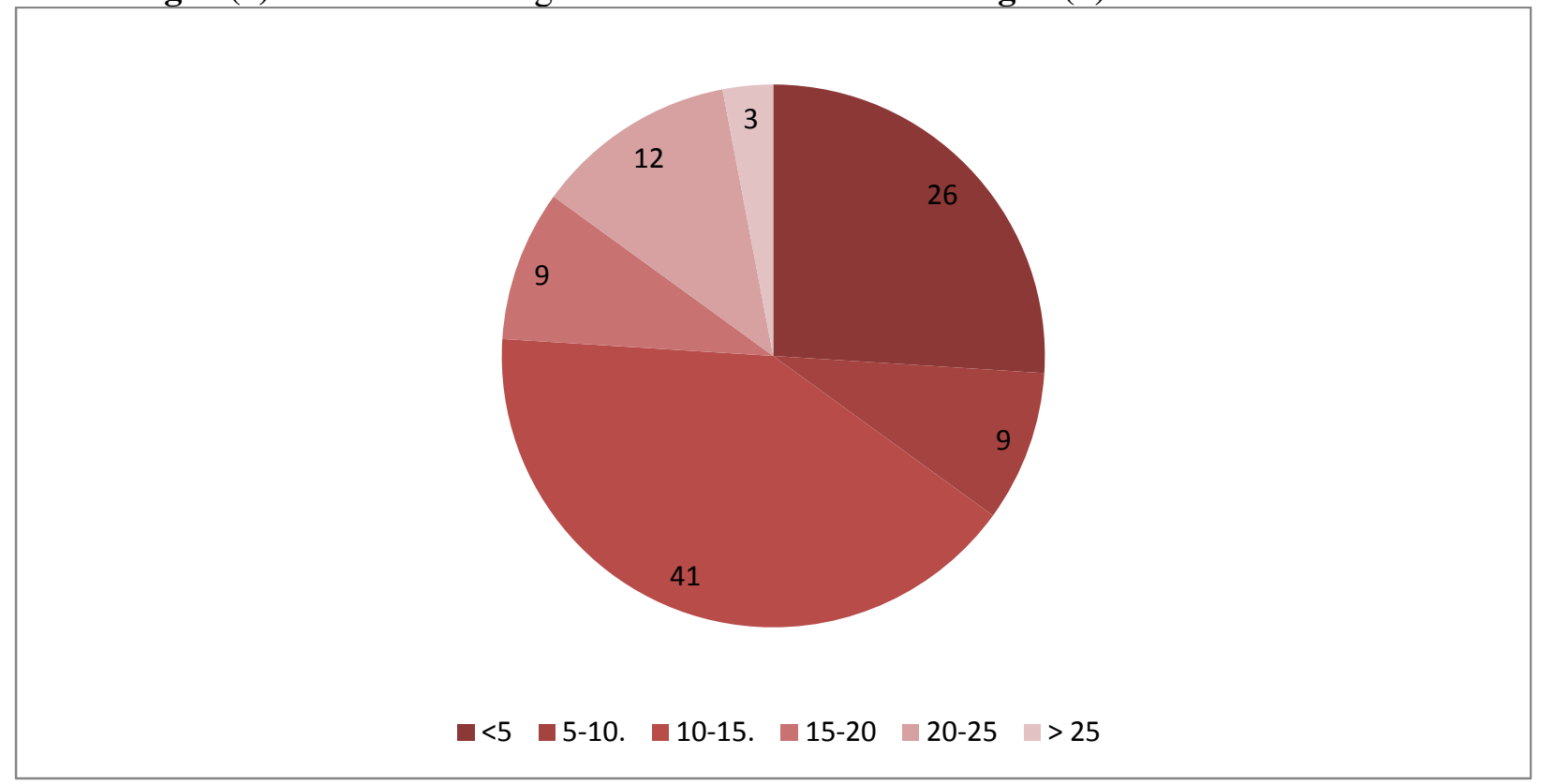

Fig. 1.(c) Years of job experience

Fig. 1. Personal characteristics of participants

In our survey, $21 \%$ of the participant aged $30-40$ and the remaining $79 \%$ were 40 to 50 years old. In terms of educational background, more participants hold university degrees and they were enrolled in related subject areas. 


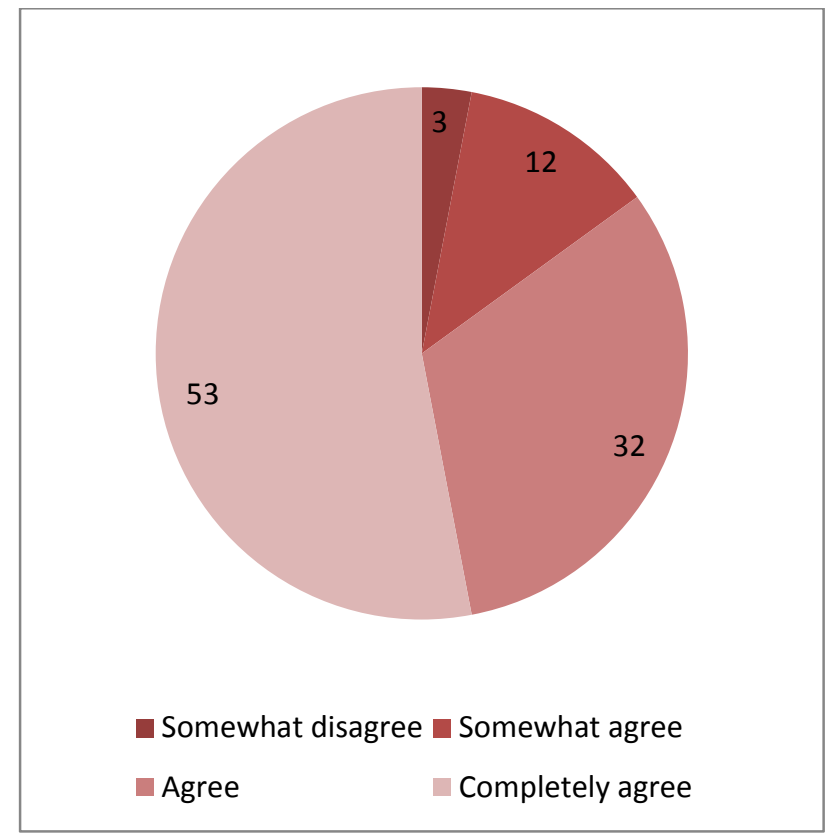

Fig. 2.(a) How IT has increased auditors' performance

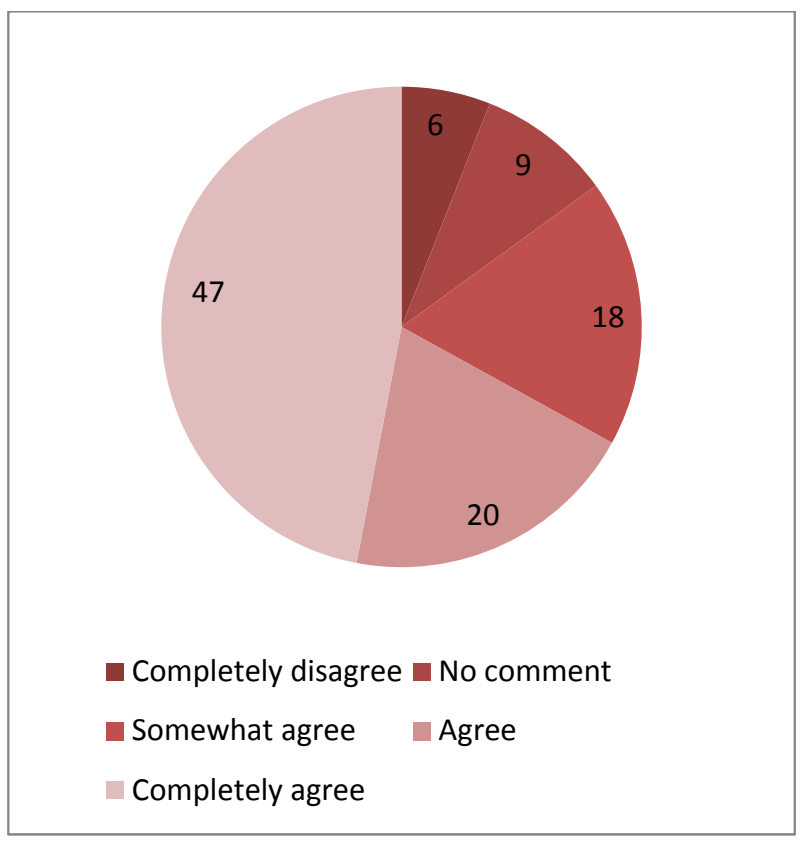

Fig. 2.(b) How IT is useful for auditors

Fig. 2. Frequency of the responses for the first hypothesis

In terms of the frequencies of the responses on questions of the first hypothesis, we can observe that $53 \%$ of the participants completely agreed that IT could increase their performance and $87 \%$ of the participants were positive that IT implementation could increase their performance. In terms of the frequencies of the effect of IT usefulness for auditors, most of them were positive about IT on increasing auditors' capabilities.

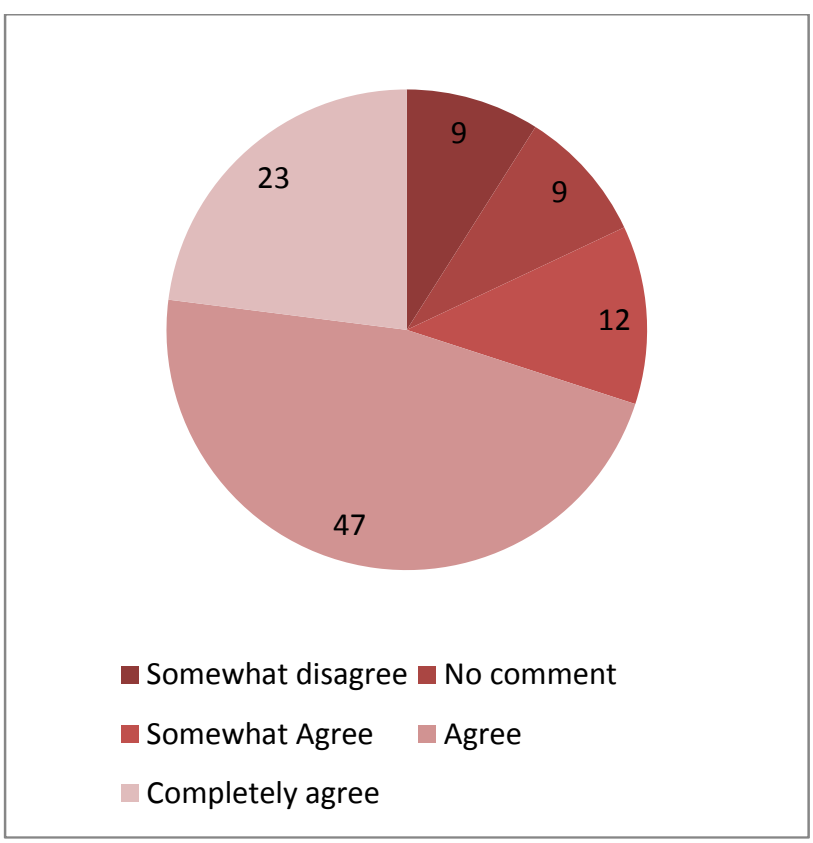

Fig. 3.(a) Learning IT is easy for auditors

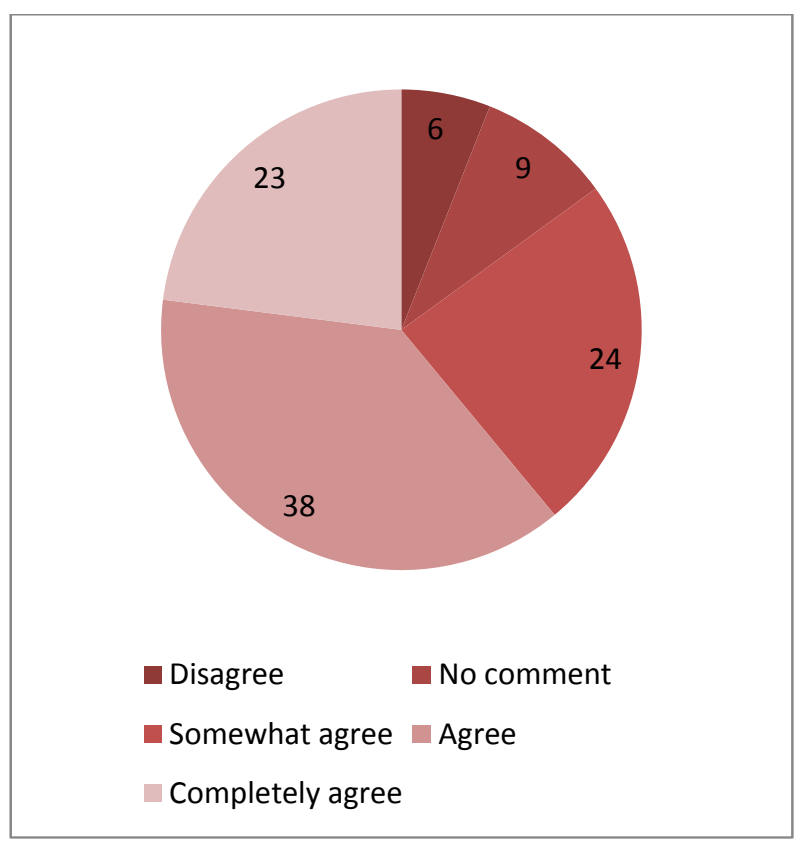

Fig. 3.(b) Implementing IT is easy for auditors

Fig. 3. Frequency of the responses for the second hypothesis 
In our survey, $70 \%$ of the participants believed that learning IT was easy for auditors and $61 \%$ of the participants stated that IT could be implemented in auditing systems, very easily.

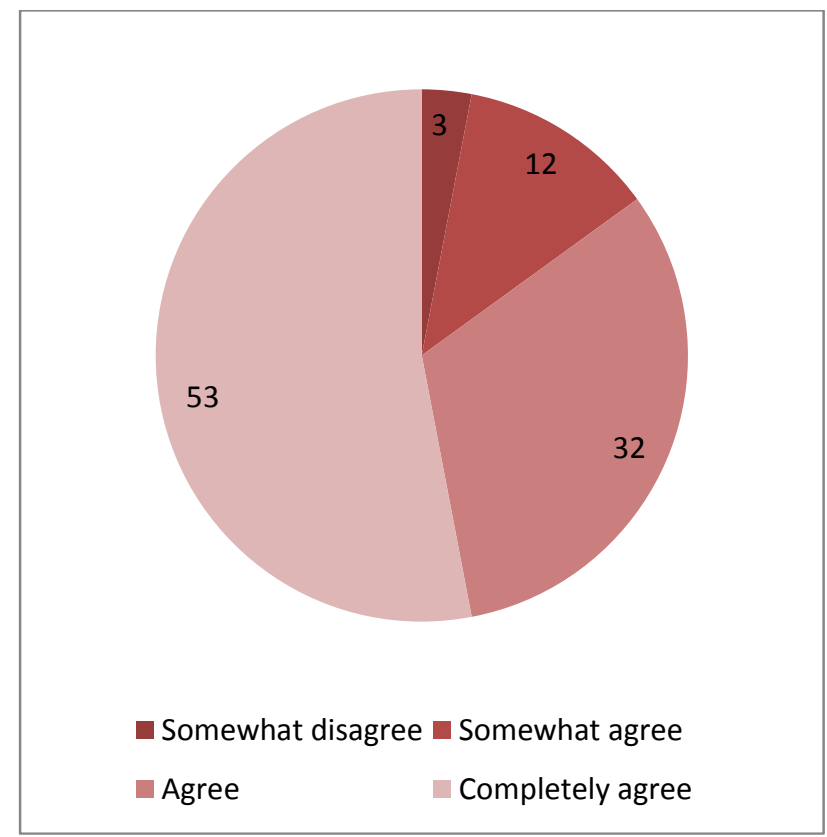

Fig. 4.(a) IT characteristics are sufficient for auditors

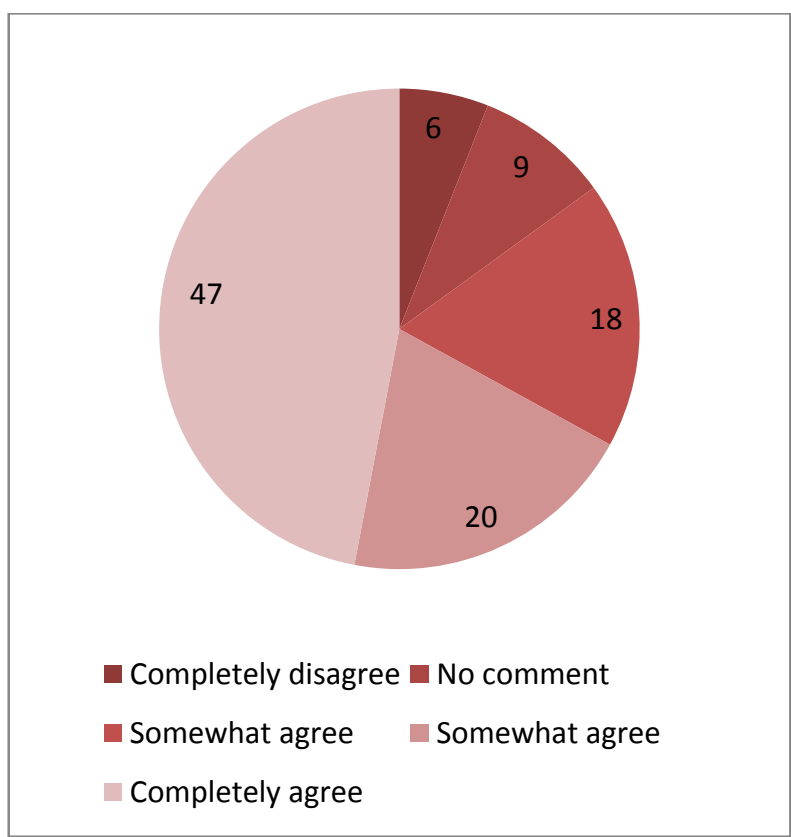

Fig. 4.(b) IT characteristics cover auditors' needs

Fig. 4. Frequency of the responses for the third hypothesis

Finally, in terms of basic statistics, $85 \%$ of the surveyed people stated that IT maintains sufficient characteristics to be implemented and $67 \%$ of them agreed that IT could fulfill their needs.

\section{The results}

To examine three main hypotheses of this survey, we have used t-student tests. We first assign a value for each seven components, i.e. Completely disagree $=1$, Somewhat disagree $=2, \ldots$, Completely agree $=7$ and measure the average of each responses. Next, we consider null hypothesis as follows,

$\mathrm{H}_{0}: \mu \leq 4$

$\mathrm{H}_{1}: \mu>4$

3.1. The first hypothesis: Relationship between a good perception in usefulness of IT implementation and accepting recent advances of IT

The first considers whether there is any relationship between a good perception in usefulness of using IT and accepting recent advances of IT. The null hypothesis considers that such relationship does not exit and the alternative hypothesis specifies that this relationship exists. The results of t-student test is equal to 14.994 and $p$-value $=0.000$. Since $t$-student is well above the critical value, 2.074, we can reject the null hypothesis and conclude that there is, indeed, a relationship between a good perception in usefulness of IT implementation and accepting recent advances of IT and auditors with good perception on IT are able to take advantage of recent advances of IT in their auditing skills.

\subsection{The second hypothesis: Relationship between accepting IT and ease of IT implementation}

The second hypothesis considers whether there is any relationship between accepting IT and ease of IT implementation. The null hypothesis considers that such relationship does not exit and the 
alternative hypothesis specifies that this relationship exists. The results of t-student test is equal to 12.868 and $p$-value $=0.000$. Since t-student is well above the critical value, 1.632 , we can reject the null hypothesis and conclude that ease of IT implementation could create motivation among auditors to automate their traditional skills.

\subsection{The third hypothesis: Relationship between accepting IT for internal auditing and confidence that IT features could completely address auditors' needs}

The third hypothesis examines whether there is any relationship between accepting IT for internal auditing and confidence that IT features could completely address auditors' needs. The null hypothesis considers that such relationship does not exit and the alternative hypothesis specifies that this relationship exists. The results of t-student test is equal to 0.267 and $p$-value $=0.791$. Therefore, we cannot reject the null hypothesis and conclude that people may be unsure on whether IT features could help them accomplish their tasks but still take advantage of recent advances of IT for auditing programs.

\subsection{The impact of personal characteristics on responses}

We have also performed Kruskal-Wallis test to find the effects of educational background, age and job experience on this questionnaire. The null hypothesis was that there was no meaningful relationship between these issues and their responses to our questionnaire. Table 1 shows details of our survey on the effect of educational background.

\section{Table 1}

The results of Kruskal-Wallis test for the effect of educational background

\begin{tabular}{lllll}
\hline Background & Number & Mean & \multicolumn{2}{c}{ Kruskal-Wallis test } \\
\hline Bachelor & 54 & 30.17 & Chi-Square & 13.056 \\
Masters & 4 & 46.00 & Degree of freedom & 2 \\
Others & 10 & 53.30 & P-Value & 0.001 \\
\hline Total & 68 & & & \\
\hline
\end{tabular}

As we can observe from the results of Table 1, Chi-square value is equal to 13.056 with $\mathrm{P}$ value $=0.001$ and this means that we can reject the null hypothesis and educational background plays an important role on our survey.

Similarly, we have investigated the impact of age on our survey and Table 2 demonstrates the results of our survey on the effect of age.

\section{Table 2}

The results of Kruskal-Wallis test for the effect of age

\begin{tabular}{lllll}
\hline Background & Number & Mean & \multicolumn{2}{c}{ Kruskal-Wallis test } \\
\hline Between 30-40 & 14 & 41.21 & Chi-Square & 2.044 \\
Between 40-50 & 54 & 32.76 & Degree of freedom & 1 \\
\hline Total & 68 & & P-Value & 0.153 \\
\hline
\end{tabular}

As we can observe from the results of Table 2, Chi-square value is equal to 2.044 with $\mathrm{P}$-value $=0.153$ and this means that we cannot reject the null hypothesis and age does not play any impact on our survey.

Finally, we have investigated the impact of job experience on our survey and Table 3 presents the results of our survey on the impact of job experience. As we can observe from the results of Table 3, Chi-square value is equal to 2.569 with $\mathrm{P}$-value $=0.766$ and this means that we cannot reject the null hypothesis and job experience does not influence on our survey. 
Table 3

The results of Kruskal-Wallis test for the impact of job experience

\begin{tabular}{lllll}
\hline Background & Number & Mean & Kruskal-Wallis test \\
\hline Less than 5 years & 6 & 29.83 & Chi-Square & 2.569 \\
Between 5-10 years & 18 & 38.83 & Degree of freedom & 5 \\
Between 10-15 years & 28 & 33.71 & & \\
Between 15-20 years & 6 & 38.83 & & \\
Between 20-25 years & 8 & 30.75 & & \\
More than 25 years & 2 & 22.50 & P-Value & 0.766 \\
\hline Total & 68 & &
\end{tabular}

\section{Conclusion}

In this survey, we have investigated whether an easy and comprehensive IT infrastructure could contribute on auditing system in Iranian banking sector. The results of our survey have indicated that there was a relationship between a good perception in usefulness of IT implementation and accepting recent advances of IT and auditors with good perception on IT are able to take advantage of recent advances of IT in their auditing skills. In addition, our survey has concluded that ease of IT implementation could create motivation among auditors to automate their traditional skills. While educational background played an important role on our survey, age and job experience did not have any impact on our survey.

\section{References}

Agarwal, R., \& Prasad, J. (1999). Are individual differences germane to the acceptance of new information technologies?. Decision Sciences, 30(2), 361-394.

Agarwal, R., Sambamurthy, V., \& Stair, R.M. (2000). The evolving relationship between general and specific computer self-efficacy - an empirical assessment. Information Systems Research, 11(4), $1-16$.

Ajzen, I., \& Fishbein, M. (1972). Attitude and normative beliefs as factors influencing intentions. Journal of Personality and Social Psychology, 21(1), 1.

Ajzen, I. (1991). The theory of planned behavior, Organizational Behavior and Human Decision Process, 50(2), 179-211.

Bandura, A. (2002). Growing primacy of human agency in adaptation and change in the electronic era. European Psychologist, 7(1), 2-16.

Burton-Jones, A. \& Hubona, G. S. (2005). Individual differences and usage behavior: revisiting a technology acceptance model assumption. Database for Advances in Information Systems, 36(2), 58-77.

Carter, f (2001). Technological Innovations: A framework for communicating diffusion effects information and management. International Journal of Information Management, 22, 42-65.

Carter, L., \& Belanger, F. (2003). Diffusion of innovation \& citizen adoption of e-government. The Fifth International Conference on Electronic Commerce (ICECR-5), Pittsburg, PA, 57-63

Carter, L., \& Bélanger, F. (2005). The utilization of e-government services: citizen trust, innovation and acceptance factors. Information Systems Journal, 15(1), 5-25.

Curran, J.M., \& Meuter, M.L. (2005). Self-service technology adoption: comparing three technologies. The Journal of Services Marketing, 19(2), 103- 114.

Davis, F. D. (1989). Perceived usefulness, perceived ease of use and user acceptance of information technology. MIS Quarterly, 13(3), 319-339.

Davis, S.A., \& Bostrom, R.P. (1993). Training end users: An experimental investigation of the roles of the computer interface and training methods. MIS Quarterly, 17(1), 61-86.

Davis, F.D., Bagozzi, R.P., \& Warshaw, P.R. (1989). User Acceptance of Computer Technology: A Comparison of Two Theoretical Models. Management Science, 35(8), 982 - 1003. 
Gefen, D., \& Straub, D.W (2000). The relative importance of perceived ease of use in IS adoption: A study of e-commerce adoption. Journal of the Association for Information Systems, 1(8), 1-19.

Gefen, D., Straud, D., \& Elena, K. (2003). Trust and TAM in online shopping: An integrated model. MIS Quarterly, 27(1), 51-90

Gist, M.E., Schwoerer, C., \& Rosen, R. (1989). Effects of alternative training methods on selfefficacy and performance in computer software training. Journal of Applied Psychology, 74(6), 884-891.

Glassberg, B.C. (2000). Individual use of web technology: A reconceptualization and empirical test of the technology acceptance model. Doctoral dissertation, University of South Carolina, 200. AAAT 9981254).

Hassan, B. (1998). The influence of computer self-efficacy and outcome expectations on computer training effectiveness. Doctoral dissertation, The University of Mississippi.

Hendrick, H., \& Brown, O. (1984). Human factors in organizational design. Amsterdam: North Holland.

Hong, W., Thong, J.Y., Wong. W., \& Tarn, K., (2002), Determinants of user acceptance of digital libraries, an empirical examinational of individual differences and system characterizes. Journal of Management Information System, 18, 97-124.

Karahanna, E., and Straub, D.W. (1999). The psychological origins of perceived usefulness and ease - of - use. Information \& Management, 35, 237-250.

Lai, V.S., \& Li, H. (2005). Technology acceptance model for internet banking: An invariance analysis. Information \& Management, 42, 373- 386.

Lee, Y., Kozar, K. A., Larsen, K. R. T. (2003). The technology acceptance model: past, present, and future. Communications of the AIS, 12, 752-780.

Luarn, P., \& Lin, H-H. (2005). Toward an understanding of the behavioral intention to use mobile banking. Computers in Human Behavior, 21(6), 873-891.

Mathieson, K. Peacock, E., \& Chin, W.W. (2001). Extending the technology acceptance model: The influence of perceived user resources. Database for Advances in Information Systems. 32(3), 86 -113.

McCormick, M.J., \& Martinko, M.J. (2004). Identifying leader social cognitions: Integrating the causal reasoning perspective into social cognitive theory. Journal of Leadership \& Organizational Studies, 10(4), 2-12.

Ndubisi, N.O. (2005). Integrating the moderation effect of entrepreneurial qualities into the technology acceptance model and treatment of potential confounding factors. Journal of Information and Science Technology, 2(1), 28-48.

Pikkarainen, T., Pikkarainen, K., Karjaluoto, \& Pahnila, S. (2004). Consumer acceptance of online banking: an extension of the technology acceptance model. Internet Research, 14(3), 224-235.

Pinto, J. and S. Mantel (1990). The causes of project failure. IEEE Transactions on Engineering Management, 37(4), 269-267.

Plouffe, C.R., Holland, J.S., \& Vandenbosch, M. (2001). Richness versus parsimony in modeling technology adoption decisions - Understanding merchant adoption of a smart card-based payment system. Information Systems Research, 12(2), 208-228.

Prussia, G.E., Anderson, J.S., \& Manz, C.C. (1998). Self leadership and performance outcomes: The mediating influence of self-efficacy. Journal of Organizational Behavior, 19, 523-538.

Shin, D. H. (2007). User acceptance of mobile Internet: Implication for convergence technologies. Interacting with Computers, 19(4), 472-483.

Tung, L. L., \& Rieck, O. (2005). Adoption of electronic government services among business organizations in Singapore. Journal of Strategic Information Systems, 14, 417-440.

Venkatesh, V. (1999). Creation of favorable user perceptions: Exploring the role of intrinsic motivation. MIS Quarterly, 23(2), 239-20.

Venkatesh, V., Morris, M.G., \& Davis, G.B. (2003). User acceptance of information technology: Toward a unified view. MIS Quarterly, 27(30), 425.

Wang, Y-S. Wang, Y-M, Lin H-H, \& Tang, T-I. (2003). Determinants of user acceptance of internet banking: An empirical study. International Journal of Service Industry Management, 14(5), pp. 501-520. 